\title{
Alexander disease type I
}

INSERM

\section{Source}

INSERM. (1999). Orphanet: an online rare disease and orphan drug data base. Alexander disease type I. ORPHA:363717

Alexander disease type I (AxD type I) is an astrog liopathy and the most severe and common form of Alexander disease (AxD; see this term), presenting before the age of 4 and characterized by seizures, megalencephaly and developmental delay with progressive deterioration. 